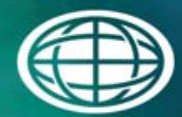

Savannah River

National Laboratory ${ }^{\mathrm{m}}$

\title{
Mixing Study for JT-71/72 Tanks
}

Si Young Lee

November 2013

SRNL-STI-2013-00702 
SRNL-STI-2013-00702

Revision 0

\section{DISCLAIMER}

This work was prepared under an agreement with and funded by the U.S. Government. Neither the U.S. Government or its employees, nor any of its contractors, subcontractors or their employees, makes any express or implied:

1. warranty or assumes any legal liability for the accuracy, completeness, or for the use or results of such use of any information, product, or process disclosed; or

2. representation that such use or results of such use would not infringe privately owned rights; or

3. endorsement or recommendation of any specifically identified commercial product, process, or service.

Any views and opinions of authors expressed in this work do not necessarily state or reflect those of the United States Government, or its contractors, or subcontractors.

Printed in the United States of America

Prepared for U.S. Department of Energy 
Keywords: Tank Mixing, Pump

Circulation, SpeciesTransport

Retention: Permanent

\section{Mixing Study for JT-71/72 Tanks}

Si Young Lee

November 2013

Prepared for the U.S. Department of Energy under contract number DE-AC09-08SR22470.

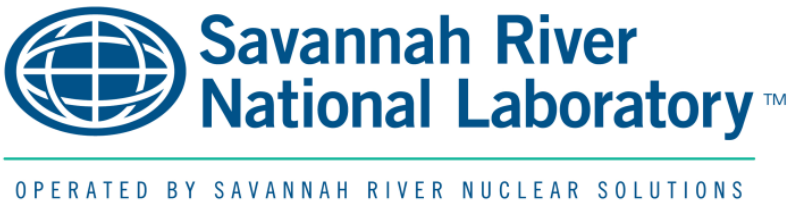




\section{EXECUTIVE SUMMARY}

All modeling calculations for the mixing operations of miscible fluids contained in HBLine tanks, JT-71/72, were performed by taking a three-dimensional Computational Fluid Dynamics (CFD) approach. The CFD modeling results were benchmarked against the literature results and the previous SRNL test results to validate the model.

Final performance calculations were performed by using the validated model to quantify the mixing time for the HB-Line tanks. The mixing study results for the JT-71/72 tanks show that, for the cases modeled, the mixing time required for blending of the tank contents is no more than 35 minutes, which is well below 2.5 hours of recirculation pump operation. Therefore, the results demonstrate the adequacy of 2.5 hours' mixing time of the tank contents by one recirculation pump to get well mixed. 


\section{TABLE OF CONTENTS}

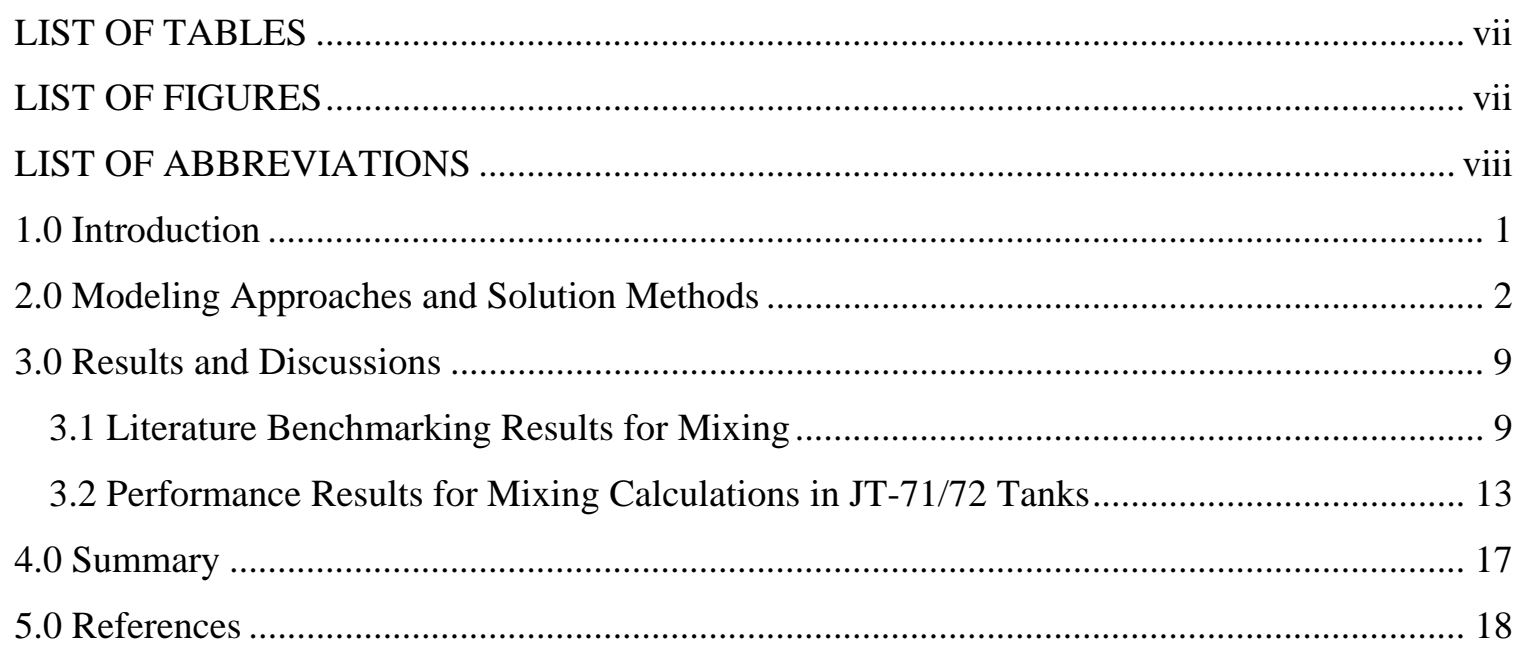




\section{LIST OF TABLES}

Table 1. Modeling conditions used for the present analysis..................................................... 6

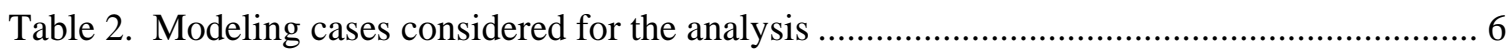

Table 3. Test conditions and literature mixing times [Ref. 3] for transient CFD calculations..... 10

Table 4. Results for the modeling cases considered for the analysis........................................ 17

\section{LIST OF FIGURES}

Figure 1. A simplified geometry for HB-Line JT-71/72 tanks [1] …......................................... 2

Figure 2. JT-71/72 modeling geometry with and without additional support structures for the mixing analysis.

Figure 5 Tank A, geometry for the demonstration runs based on two different approaches of transient flow pattern and species transport calculations ........................................... 10

Figure 6. Fully developed flow patterns used as the initial flow conditions for the transient transport calculations using tracer species............................................................ 11

Figure 7. Lagrangian flow path lines from jet inlet to tank exit for fully developed flow circulation inside a tank during blending

Figure 8. Comparison of transient time snapshots for flow patterns of species concentration at vertical central plane through the pump nozzle center line $(*$ Non-dimensionalized by equilibrium species concentration of $3.02 \times 10^{-4}$; literature blending time results $=32$ seconds)

Figure 9. Benchmarking results of theoretical tank blending time compared to experimental test results [6].....

Figure 10. Circulation flow patterns and flow distributions before species injection (Case A1). 14

Figure 11. Transient species mass fractions during the mixing period (Case A1)...................... 15

Figure 12. Transient non-dimensional mass fractions for Case A1 ............................................ 16 


\section{LIST OF ABBREVIATIONS}

\begin{tabular}{|c|c|}
\hline A & Area \\
\hline C & Concentration or constant for equation \\
\hline $\mathrm{C}_{\mathrm{eq}}$ & Equilibrium concentration \\
\hline D & Tank diameter \\
\hline$D_{v}$ & Molecular diffusion coefficient \\
\hline $\mathrm{d}_{\mathrm{o}}$ & Pump nozzle diameter \\
\hline$E$ & Kinetic energy \\
\hline g & Gravitational acceleration \\
\hline $\overrightarrow{\mathrm{J}}_{v}$ & Diffusion flux of tracer species \\
\hline$k$ & Turbulent kinetic energy per unit mass \\
\hline $\mathrm{L}$ & Jet length or maximum integral length scale \\
\hline $\mathrm{p}$ & Pressure \\
\hline$\Delta \mathrm{p}$ & Pressure drop \\
\hline Q & Volumetric flow rate \\
\hline $\mathrm{Q}_{\mathrm{j}}$ & Jet volumetric flow rate \\
\hline $\mathrm{R}$ & Tank or pipe radius \\
\hline $\mathrm{R}_{\mathrm{s}}$ & Jet spreading rate \\
\hline r & Local radial distance of turbulent jet region \\
\hline$S_{V}$ & Source term of tracer species \\
\hline $\mathrm{t}$ & Time \\
\hline $\mathrm{Sc}_{\mathrm{t}}$ & Turbulent Schmidt number (= Ratio of momentum to mass diffusion) \\
\hline$t_{m}$ & Mixing time \\
\hline $\mathrm{U}_{\mathrm{o}}$ & Velocity at pump inlet \\
\hline$x$ & Local distance along the $\mathrm{x}$-axis \\
\hline$Y_{v}$ & Local mass fraction of tracer species \\
\hline$\varepsilon$ & Turbulent energy dissipation rate per unit mass \\
\hline$\varepsilon_{V}$ & Turbulent energy dissipation rate per unit volume \\
\hline$\rho$ & Fluid density \\
\hline$\lambda$ & Turbulent length scale \\
\hline$\mu_{t}$ & Turbulent dynamic viscosity $\left(=\rho v_{t}\right)$ \\
\hline$v$ & Kinematic viscosity \\
\hline$v_{\mathrm{t}}$ & Turbulent eddy diffusion coefficient \\
\hline $\operatorname{Re}$ & Reynolds number \\
\hline CFD & Computational Fluid Dynamics \\
\hline FLUENT & CFD software code \\
\hline
\end{tabular}


SRNL-STI-2013-00702

Revision 0

\subsection{Introduction}

The HB-Line Engineering Organization requested that Savannah River National Laboratory (SRNL) evaluate methods to mix and blend the solution contents of the JT$71 / 72$ tanks to ensure the contents are properly mixed. This work focuses on the estimate of mechanical mixing time of two miscible liquids related to the turbulent dispersion circulated by the pump, while ensuring that the solutions are mixed adequately.

The primary objective of this work is to quantify the mixing time when two miscible fluids are mixed by one recirculation pump and to evaluate adequacy of 2.5 hours of pump recirculation to be considered well mixed in HB-Line tanks, JT-71/72. The work scope described here consists of two modeling analyses. They are the steady state flow pattern analysis during pump recirculation operation of the tank liquid and transient species transport calculations based on the initial steady state flow patterns. The modeling calculations for the mixing time are performed by using the $99 \%$ homogeneity criterion for the entire domain of the tank contents.

The detailed tank geometry for $\mathrm{JT}-71 / 72$ tanks equipped with one recirculation pump is provided in the drawing, D127930 [1]. A simplified modeling geometry was considered for the mixing analysis as shown in Fig. 1. This tank has 7-turn helical cooling coils with 2 inches in coil diameter and 42 inches in loop diameter. Tank fluid is pumped out by the submerged nozzle inlet with 2.125 inches diameter located at about 1.5 inches above the tank floor, and it is discharged back to the top surface of the tank liquid. The tank contents are dispersed and mixed mainly by $15 \mathrm{gpm}$ recirculation flow through the submerged nozzle inlet.

All modeling calculations for the mixing operations are performed by a three-dimensional Computational Fluid Dynamics (CFD) approach. The CFD modeling results are benchmarked against the literature results [2] and the previous SRNL test results [5] to validate the model. Final performance calculations were performed by using the validated model to quantify the mixing time for the HB-Line tanks JT-71/72 and to demonstrate the adequacy of 2.5 hours' mixing time of the tank contents by one recirculation pump to get well mixed. 


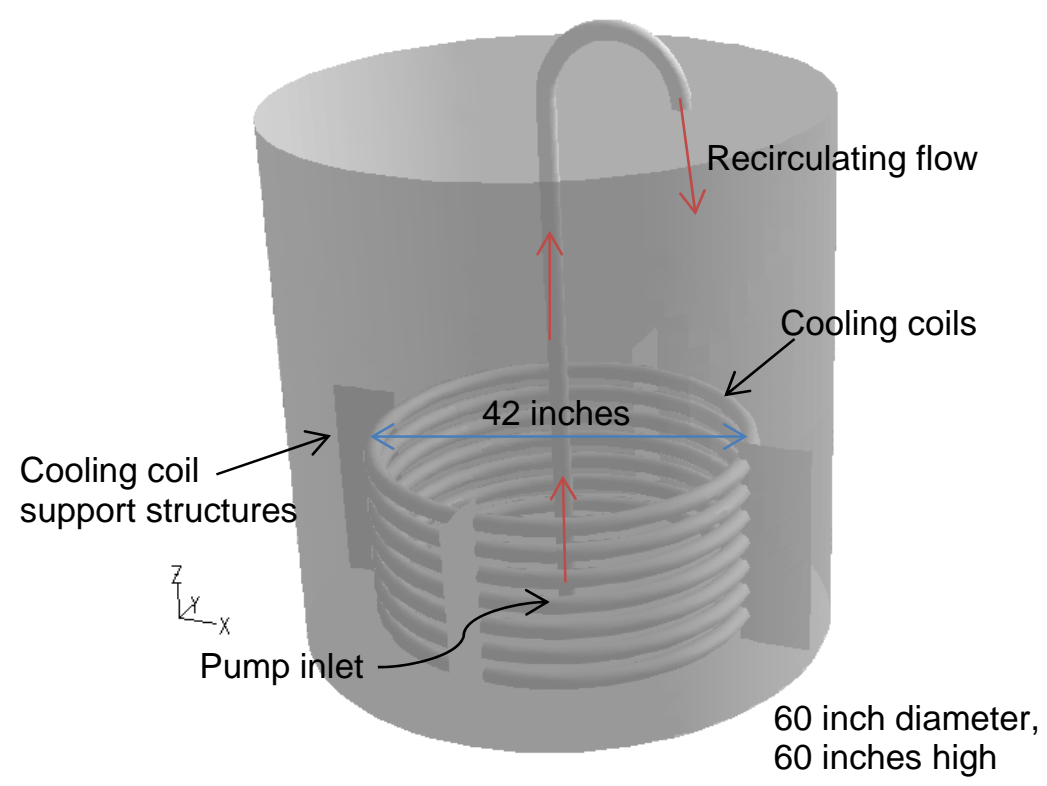

Figure 1. A simplified geometry for HB-Line JT-71/72 tanks [1]

\subsection{Modeling Approaches and Solution Methods}

For the present analysis, a three-dimensional computational fluid dynamics (CFD) approach was taken to calculate flow velocity distributions, and to estimate mixing time for two miscible liquids; such as, solution and acid, for Tank JT-71/72 as illustrated in Fig. 1. The results are benchmarked against both the literature data and SRNL test data [2]. The commercial finite volume code, FLUENT, was used to create a full scale geometry file in a non-orthogonal mesh environment.

The prototypic model geometry was created on the computational domain by using the body-fitted coordinate system and structured multi-block grids. For the mixing performance analysis, the reference design conditions were considered as shown in Fig. 1 and Table 1. The circulation pump is submerged for the mixing inside a cylindrical tank that is 60 in high and about 60 in diameter. The $15 \mathrm{gpm}$ flowrate is pulled through 2.125-inch nozzle inlet installed at about 1.5 inches above the tank floor, and it is discharged back to the top surface of the tank liquid. This tank has 7-turn helical cooling coils with 2 inches in coil diameter and 42 inches in loop diameter.

For the calculations, the transient governing equations consisting of one mass balance, three momentum equations along the Cartesian coordinate system, two turbulence transport equations for kinetic energy $(k)$ and dissipation rate $(\varepsilon)$, and one species transport were solved by an iterative technique until the species concentrations of tank fluid were reached at equilibrium concentration within $1 \%$ relative error. For $\mathrm{C}_{\text {eq }}$ the equilibrium concentration and $C$ the transient concentration at a monitoring point, the 99\% mixing time $t_{m}$ was defined by 
$\mathrm{t}_{\mathrm{m}}=\left|\frac{\mathrm{C}-\mathrm{C}_{\mathrm{eq}}}{\mathrm{C}}\right|<0.01$

The steady-state flow solutions for the entire tank fluid were used for the initial conditions.

In the present analysis, the present work used the assumptions as follows:

- Top tank liquid surface was assumed to be frictionless for computational efficiency, neglecting the detailed wave motion of the free surface. That behavior does not have a significant impact on the flow patterns inside the slurry region in a deep tank.

- The fluid properties of water or acid solution were evaluated at values to conservatively evaluate the system.

- The flow conditions for the pump operations are assumed to be fully turbulent since Reynolds numbers for typical operating conditions are in the range of 1 $\times 10^{4}$ to $3.0 \times 10^{4}$ based on the pump nozzle inlet conditions (2.125 inch inlet diameter).

- Cooling coils and their supporting structures are considered as major flow obstructions, assuming that detailed small objects attached to the inner wall of the tank have negligible impact on the mixing time due to flow recirculation

A standard two-equation turbulence model, the $\kappa-\varepsilon$ model [3], was used to capture the turbulent flow evolution driven by the blending circulation pump since the previous work $[2,3]$ showed that the two-equation model predicts the flow evolution of turbulent jet in a large stagnant fluid domain with reasonable accuracy. This model specifies the turbulent or "eddy" viscosity $v_{t}$ by the empirical equation.

$v_{t}=\frac{\mu_{t}}{\rho_{f}}=\left(\frac{C_{\mu} k^{2}}{\varepsilon}\right)$

In Eq. (2), $C_{\mu}$ is an empirical constant. In the present calculations, $C_{\mu}$ is 0.09 . Thus, the turbulent viscosity is computed by solving two transport equations for $k$ (turbulent kinetic energy), and $\varepsilon$ (rate of dissipation of turbulent energy).

From these two key parameters of $k$ and $\varepsilon$, a length scale $\left(k^{1.5} / \varepsilon\right)$, a timescale $(k / \varepsilon)$, a quantity of turbulent eddy diffusivity $\left(k^{2} / \varepsilon\right)$, can be formed without specification of flowdependent mixing length scale $\lambda[7]$. Turbulence kinetic energy $(k)$ is the mean kinetic energy per unit mass associated with eddies in turbulent flow. Physically, the turbulence kinetic energy is characterized by measured root-mean-square (rms) velocity fluctuations. In the Reynolds-averaged Navier Stokes equations, the turbulence kinetic energy can be calculated based on the closure method, i.e. a turbulence model. Generally, the turbulent kinetic energy can be quantified by the mean of the turbulence normal stresses:

$k=\frac{1}{2}\left\{\overline{\left(u_{x}\right)^{2}}+\overline{\left(u_{y}\right)^{2}}+\overline{\left(u_{z}\right)^{2}}\right\}$ 
$k$ can be produced by fluid shear, friction or buoyancy, or through external forcing at lowfrequency eddy scales (integral scale). Turbulence kinetic energy is then transferred down the turbulence energy cascade, and is dissipated by viscous forces at the Kolmogorov scale. This process of production, convective transport and dissipation as modeled for $k$ transport balance in the two-equation turbulence model can be expressed as:

$\frac{D k}{D t}=\nabla \cdot\left(\frac{v_{T}}{\sigma_{k}} \nabla k\right)+P-\varepsilon$

The three other terms, $-D k / D t, P$, and $\varepsilon$, are in closed form given the turbulent-viscosity hypothesis.

Turbulence consists of high levels of fluctuating vorticity. At any instant, vortical motion called eddies are present in the flow. These eddies range in size from the largest geometrical scales of the flow; such as, tank diameter, down to small eddies where molecular diffusion dominates. The eddies are continuously evolving, and the superposition of their induced motions leads to the fluctuating waves. In this situation, turbulent kinetic energy is dissipated from the largest eddies down to the smallest through a process called energy cascade. In order to maintain the turbulence, a constant supply of energy must be fed to the turbulent fluctuations at the largest scales from the mean motions, where it is driven by a jet pump or mechanical agitator. Thus, turbulent energy dissipation rate $\varepsilon$ is viewed as the energy-flow rate in the cascade, and it is determined by the large-scale motions, independent of the viscosity at high Reynolds number. Consequently, the transport equation for $\varepsilon$ is best considered as being entirely empirical. That is,

$\frac{D \varepsilon}{D t}=\nabla \cdot\left(\frac{v_{t}}{\sigma_{\varepsilon}} \nabla \varepsilon\right)+C_{1}\left(\frac{\varepsilon}{k}\right) P-C_{2} \frac{\varepsilon^{2}}{k}$

The governing equations to be solved for the present work are composed of one continuity equation, three momentum equations for the three component directions $(x, y$, and $z$ directions), and two constitutive equations for the turbulence descriptions. The detailed descriptions for the governing equations and computational methods are provided in the previous work [3].

When a tracer species, such as acid material, is added to the tank during mixing operations before transfer of the tank contents, the added species is transported over the tank domain by the continuous fluid motion driven by the pump. The modeling calculations for the mixing time require the balance equation of tracer species. The species balance equation is given by

$\frac{\partial \rho Y_{v}}{\partial t}+\nabla \cdot\left(\rho \vec{v} Y_{v}\right)=-\nabla \cdot \vec{J}_{v}+S_{v}$

$Y_{v}$ is local mass fraction of tracer species in the continuous fluid. $\vec{J}_{v}$ is diffusion flux of tracer species. $S_{V}$ in the equation is a source term of tracer species added to the tank fluid due to the injection of the acid from the top of tank. The diffusion flux of tracer under turbulent fluid flow is computed by 
$\vec{J}_{v}=-\left(\rho D_{v}+\frac{\mu_{t}}{S c_{t}}\right) \nabla Y_{v}$

$D_{v}$ is molecular diffusion coefficient of tracer in the continuous fluid medium. Typical molecular diffusion coefficient of liquid species in the liquid domain is about $1 \times 10^{-9}$ $\left(\mathrm{m}^{2} / \mathrm{sec}\right)$, which is much smaller than gas species.

The governing equations described above are solved over the entire tank domain with and without cooling coil supports as shown in Fig. 2. For the calculations, the domain was meshed by a hexahedral meshing technique. The number of mesh nodes for the domain with cooling coils was established as about $5 \times 10^{5}$ nodes as shown in Fig. 3 . The number of mesh nodes for the model with cooling coils and support structure was about $6 \times 10^{5}$. Figure 4 shows three-dimensional computational volume meshes for the domain including the cooling coils and the coil support structures.

A mixing model of the tank configuration was set up with the return path reflecting the actual tank configuration as defined in engineering drawing [1]. The modeling domain and configurations for the tanks without and with support structures of cooling coils are shown in Fig. 6. As shown in the figure, a pump connected with vertical pipe is located near the tank bottom 1.5 inches above the tank, and the pumped flow returns to the tank through the 1.5 inch pipe submerged on top liquid surface. In this case, the species fluid was an acid of 1.235 specific gravity and $3 \mathrm{cp}$ viscosity, and total volume injected through the 2.125 inch hole was about 0.6 gallons for the initial period of 10 seconds. The acid was injected at the middle of tank radius as schematically shown in Fig. 1. Detailed configurations performed for the calculations are shown in Fig. 1. The transient species profile was then calculated and observed for estimation of the mixing time.

The modeling results were benchmarked against the literature data and the previous SRNL test results [2]. The validated model was applied for a series of the modeling calculations to estimate the mixing times for nominal operating conditions and to investigate the impact of the flow obstructions and fluid properties on the mixing time. The mixing calculations for two separate cases were performed. The first case is the transient calculations of the species concentration in a tank with cooling coils. The second calculations are for the tank fluid with cooling coils combined with supporting structures as built in JT-71/72 tank [1]. In each case, three different property models for a combination of high/low end densities and viscosities were developed. All detailed modeling conditions considered here are summarized in Table 1. 
Table 1. Modeling conditions used for the present analysis

\begin{tabular}{|l|c|}
\hline \multicolumn{1}{|c|}{ Parameters } & Values \\
\hline Tank diameter (inches) & 60 \\
\hline Tank level (inches) & 60 \\
\hline Cooling coil loop diameter (inches) & 42 \\
\hline Cooling coil diameter (inches) & 2 \\
\hline Number of cooiling coil turns & 7 \\
\hline Cooling coil pitch height (inches) & 3 \\
\hline Bulk fluid density $\left(\mathrm{kg} / \mathrm{m}^{3}\right)$ & 1150,1235 \\
\hline Bulk fluid viscosity $(\mathrm{cp})$ & $1.0,3.0$ \\
\hline Tracer fluid species density $\left(\mathrm{kg} / \mathrm{m}^{3}\right)$ & $1000,1100,1235$ \\
\hline Tracer fluid species viscosity $(\mathrm{cp})$ & $1.0,3.0$ \\
\hline Recirculation pump flowrate $(\mathrm{gpm})$ & 15 \\
\hline Pump suction diameter (inches) & 2.125 \\
\hline Pump discharge diameter (inches) & 1.5 \\
\hline
\end{tabular}

Table 2. Modeling cases considered for the analysis

\begin{tabular}{|c|c|c|c|}
\hline Modeling cases & Modeling geometry & \multicolumn{2}{|c|}{ Operating conditions } \\
\hline \multirow{2}{*}{ Case A1 } & \multirow{2}{*}{$\begin{array}{l}\text { Cooling coils } \\
\text { included }\end{array}$} & Bulk fluid & $\begin{array}{c}\text { Specific gravity: } 1.150 \\
\text { Viscosity: } 1 \mathrm{cp}\end{array}$ \\
\hline & & $\begin{array}{l}\text { Species to } \\
\text { be mixed }\end{array}$ & $\begin{array}{l}\text { Specific gravity: } 1.100 \\
\text { Viscosity: } 1 \mathrm{cp}\end{array}$ \\
\hline \multirow{2}{*}{ Case A2 } & \multirow{2}{*}{$\begin{array}{l}\text { Cooling coils } \\
\text { included }\end{array}$} & Bulk fluid & $\begin{array}{c}\text { Specific gravity: } 1.235 \\
\text { Viscosity: } 3 \mathrm{cp}\end{array}$ \\
\hline & & $\begin{array}{l}\text { Species to } \\
\text { be mixed }\end{array}$ & $\begin{array}{c}\text { Specific gravity: } 1.235 \\
\text { Viscosity: } 3 \mathrm{cp}\end{array}$ \\
\hline \multirow{2}{*}{ Case A3 } & \multirow{2}{*}{$\begin{array}{l}\text { Cooling coils } \\
\text { included }\end{array}$} & Bulk fluid & $\begin{array}{l}\text { Specific gravity: } 1.235 \\
\text { Viscosity: } 3 \mathrm{cp}\end{array}$ \\
\hline & & $\begin{array}{l}\text { Species to } \\
\text { be mixed }\end{array}$ & $\begin{array}{l}\text { Specific gravity: } 1.0 \\
\text { Viscosity: } 1 \mathrm{cp}\end{array}$ \\
\hline \multirow{2}{*}{ Case B } & \multirow{2}{*}{$\begin{array}{l}\text { Cooling coils and } \\
\text { supporting } \\
\text { structures included }\end{array}$} & Bulk fluid & $\begin{array}{c}\text { Specific gravity: } 1.235 \\
\text { Viscosity: } 3 \mathrm{cp}\end{array}$ \\
\hline & & $\begin{array}{l}\text { Species to } \\
\text { be mixed }\end{array}$ & $\begin{array}{l}\text { Specific gravity: } 1.0 \\
\text { Viscosity: } 1 \mathrm{cp}\end{array}$ \\
\hline
\end{tabular}




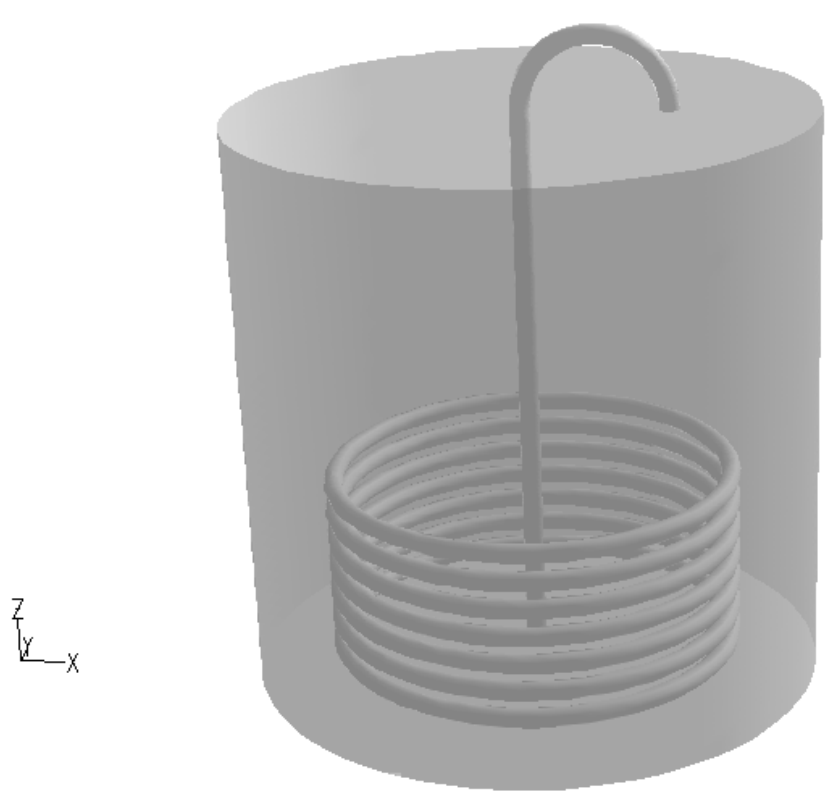

(Modeling geometry with cooling coils only)

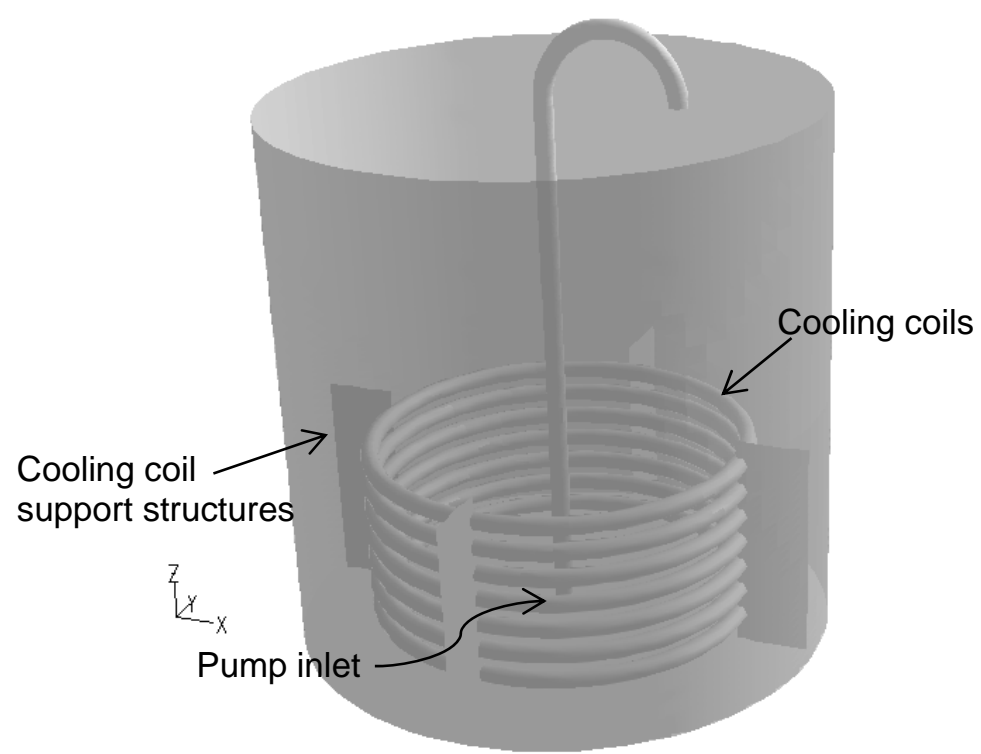

(Modeling geometry with cooling coils and their supporting structures)

Figure 2. JT-71/72 modeling geometry with and without additional support structures for the mixing analysis 
SRNL-STI-2013-00702

Revision 0

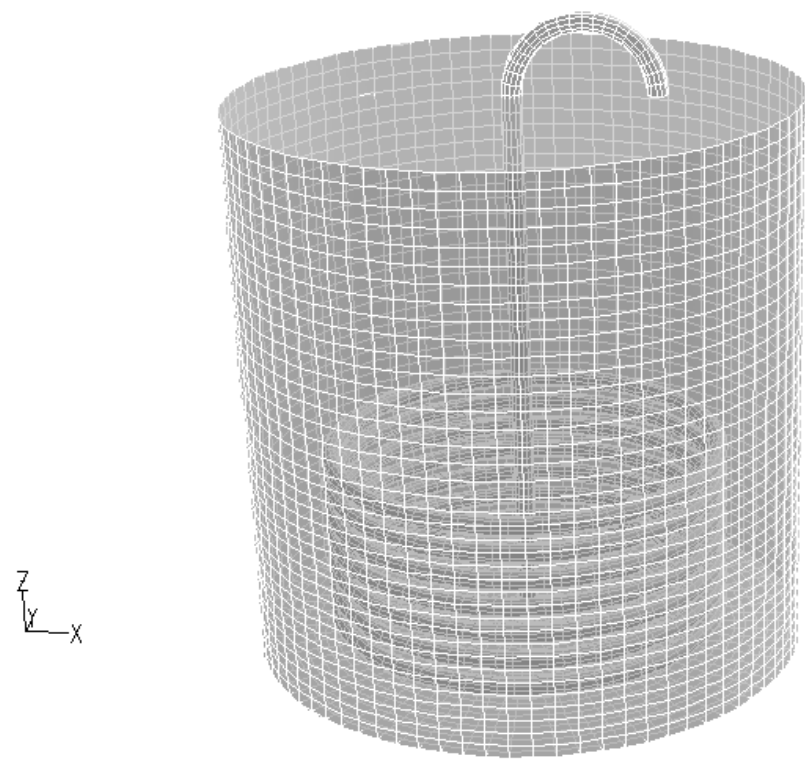

Figure 3. Computational meshes for the JT-71 tank mixing analysis ( $5 \times 10^{5}$ meshes)

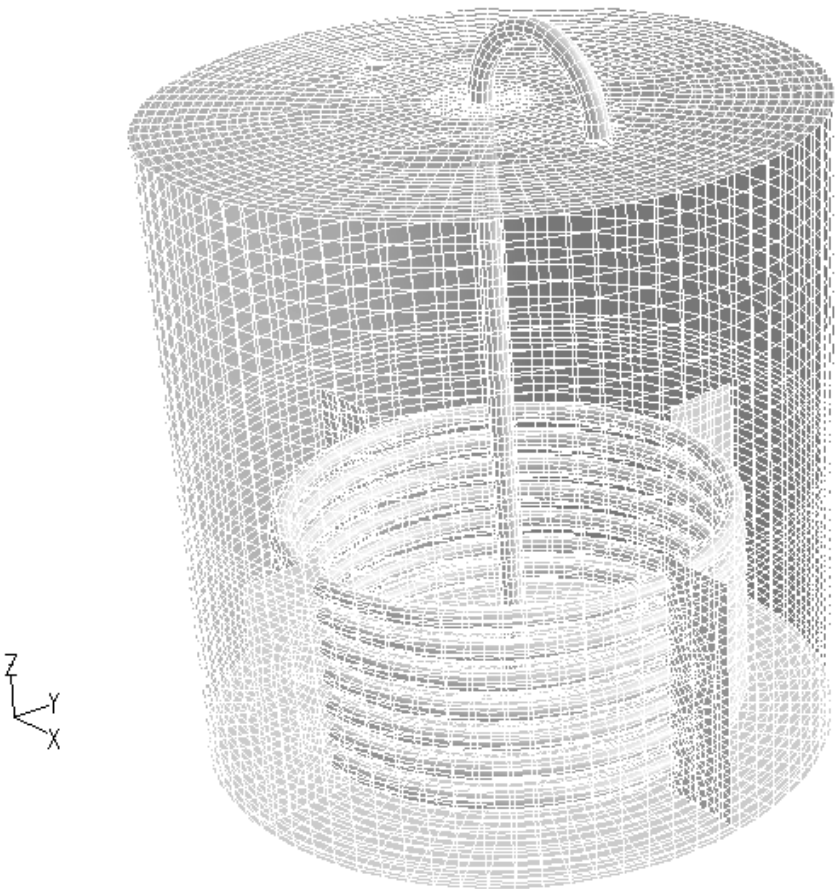

Figure 4. Computational meshes for the JT-71 tank mixing analysis coupled with cooling coil support structure $\left(6 \times 10^{5}\right.$ meshes $)$ 


\subsection{Results and Discussions}

Based the two-step approach, the modeling calculations were made for the numerical simulation as performed for the mixing operation. The first step is to establish the steady-state flow patterns of submersible pump flows as performed for the pump recirculation. The second step is to perform the transient modeling calculations starting with another set of species balance equation in addition to the continuity, momentum, and two turbulence equations. In this approach, the transient calculations were started from the fully developed flow distribution of the first step steady-state runs as initial conditions. For the second step, a transient run was started with acid species injected into the fully-developed flow pattern established by the first step, and run until the species was mixed with continuous bulk phase in a homogeneous way within $99 \%$. A contaminant species started from the fully developed condition of the first step in which the species was injected for 10 seconds into the 2 inch hole at the top of the tank. In this case, the species fluid has properties of 1.0 specific gravity and $1.0 \mathrm{cp}$ viscosity, and total volume injected through the hole was about 0.6 gallons for the initial period of 10 seconds. The transient contaminant profile was calculated and observed.

The benchmarking tests are chosen as two typical areas representing the turbulent pump dissipations, and flow dispersion behavior since these two phenomena are closely related to the miscible fluid mixing and species dispersion mechanisms within the bulk fluid space of the tank with flow obstructions. One is the momentum dissipation area directly impacted by the submerged flow parameter, product of pump inlet velocity and pump diameter $U_{o} d_{o,}$, and the other one is the remote area near the flow obstructions indirectly influenced by forced convective circulation. Both of the benchmarking areas are closely related to the mixing times of the miscible tank contents, and the spread behavior of the injected species. The detailed results are provided in the subsequent section.

\subsection{Literature Benchmarking Results for Mixing}

A benchmarking model of the Tank A configuration shown in Table 3 was developed with the return path reflecting the actual tank configuration as described by Grenville and Tilton [5]. The model configuration is shown in Figure 5. As shown in the figure, a jet pump with $42.6^{\circ}$ upward angle is located at the tank bottom, and the jetted flow returns to the pump through the tank bottom. Based on this model, the present two-step method was applied to estimate the blending time for benchmarking of Grenville's experimental work. In this approach, the transient calculations were again started from the fully developed flow distribution of the first step runs as initial conditions. The second step simulated the mixing tests performed by Grenville and Tilton [5]. Figure 6 shows the fully developed flow patterns established by the first step. The second step was a transient calculation for a contaminant species started from the fully developed condition of the first run in which the species was injected for 10 seconds into the inlet jet. In this case, the species fluid was an acid with a 1.14 specific gravity and a $1.16 \mathrm{cp}$ viscosity, where the total volume injected through a $10 \mathrm{~mm}$ hole was approximately 0.21 gallons for an initial period of 10 seconds. Detailed test configurations and the computational domain of the Tank A system are shown in Figure 5. The transient species profile was then calculated and observed. Figure 7 shows Lagrangian flow path lines from the pump inlet to the tank exit for fully developed flow circulation inside the tank during the mixing period. 
For comparison of the species blending time with flow evolution time, a transient run with no species addition was started from stagnant tank fluid conditions and run until fully developed steady state flow patterns were established. The results of Table 3 are consistent with the two-step results shown in Figure 8 . Comparison of transient snapshots between species concentration and flow patterns at a vertical central plane crossing the pump nozzle exit is made in Figure 15, indicating that the tank blending time is shown to be about 33 seconds, which is in agreement with Grenville's measured results of 32 seconds to within about $3 \%$. In the figure, species concentration was nondimensionalized in terms of equilibrium species concentration of $3.02 \times 10^{-4}$. The results show very clearly that the injected contaminant species follows the velocity profile and that the propagation of the contaminant species develops over the same time period as both the bulk flow and the eddy flow patterns. From the previous results [6], the benchmarking results for blending time are shown in Fig. 9. These results demonstrated that the CFD models predicted the test results for a range of jet $U_{0} d_{0}$ operating conditions within about $20 \%$.

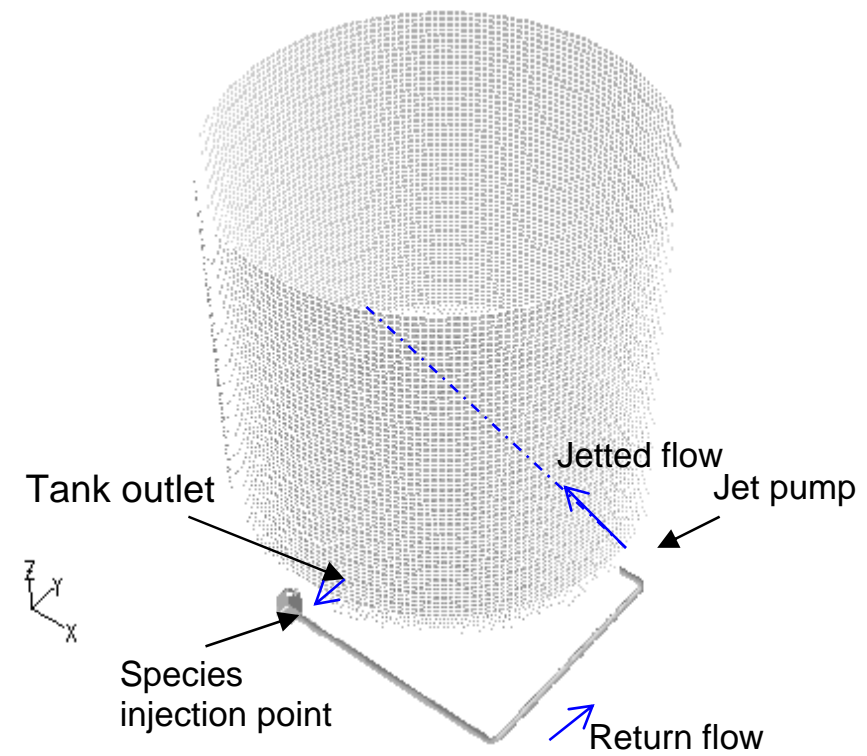

Figure 5 Tank A, geometry for the demonstration runs based on two different approaches of transient flow pattern and species transport calculations

Table 3. Test conditions and literature mixing times [Ref. 3] for transient CFD calculations

\begin{tabular}{|c|c|c|c|c|c|c|c|}
\hline Tank & $\begin{array}{c}D \\
\text { (Tank dia.) }\end{array}$ & $\begin{array}{c}h_{l} \\
\text { (liquid } \\
\text { height) }\end{array}$ & $\begin{array}{c}\text { Inclination } \\
\text { angle of Jet }\end{array}$ & $\begin{array}{c}d_{o} \\
\text { (jet dia.) }\end{array}$ & $\begin{array}{c}U_{o} \\
\mathrm{~m} / \mathrm{se} \\
\mathrm{c}\end{array}$ & $R e_{j e t}$ & $\begin{array}{c}\text { Mixing time by } \\
\text { G-T correlation } \\
{[5]}\end{array}$ \\
\hline Tank A & $1.68 \mathrm{~m}$ & $1.55 \mathrm{~m}$ & $42.6^{\circ}$ & $\begin{array}{c}26.1 \\
\mathrm{~mm}\end{array}$ & 19.8 & 516,780 & $32 \mathrm{sec}$. \\
\hline
\end{tabular}

Note: * Jet is located at the corner of tank bottom as shown in Figure 5. 

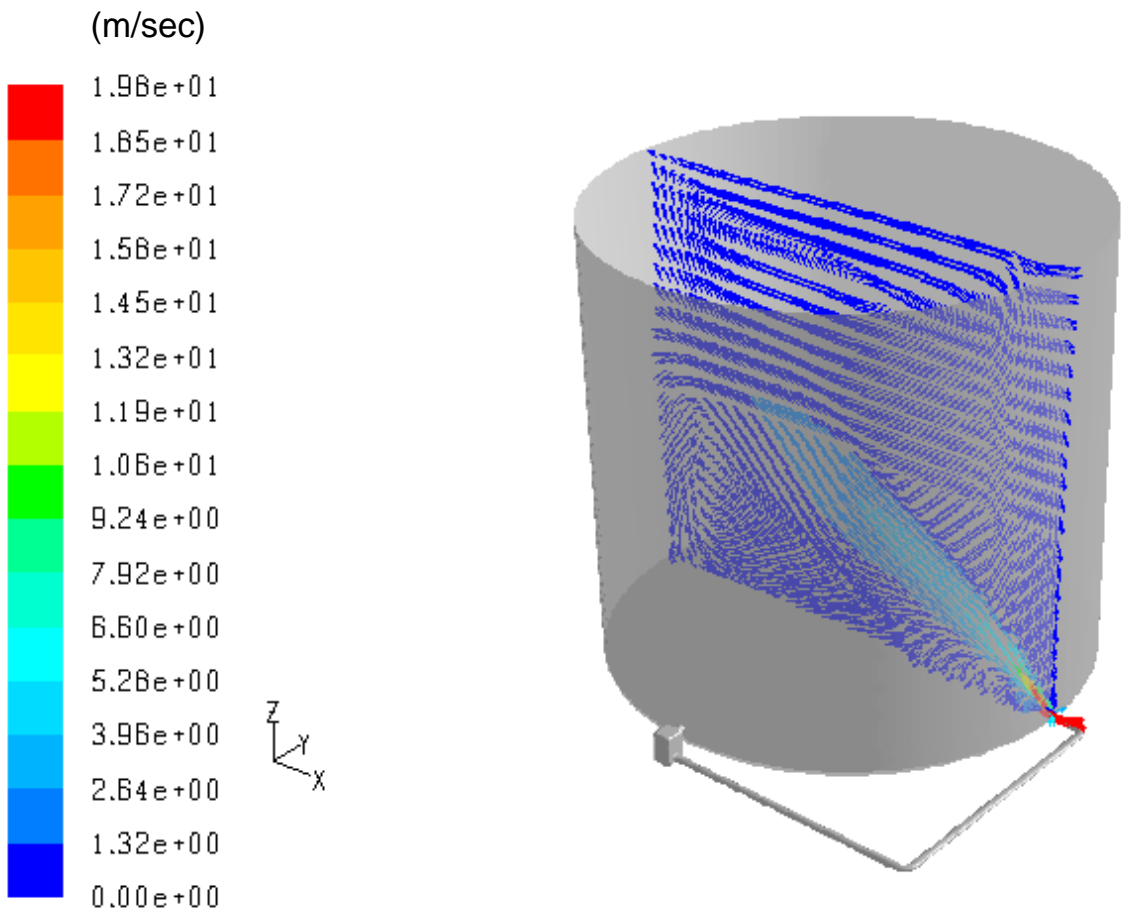

Figure 6. Fully developed flow patterns used as the initial flow conditions for the transient transport calculations using tracer species

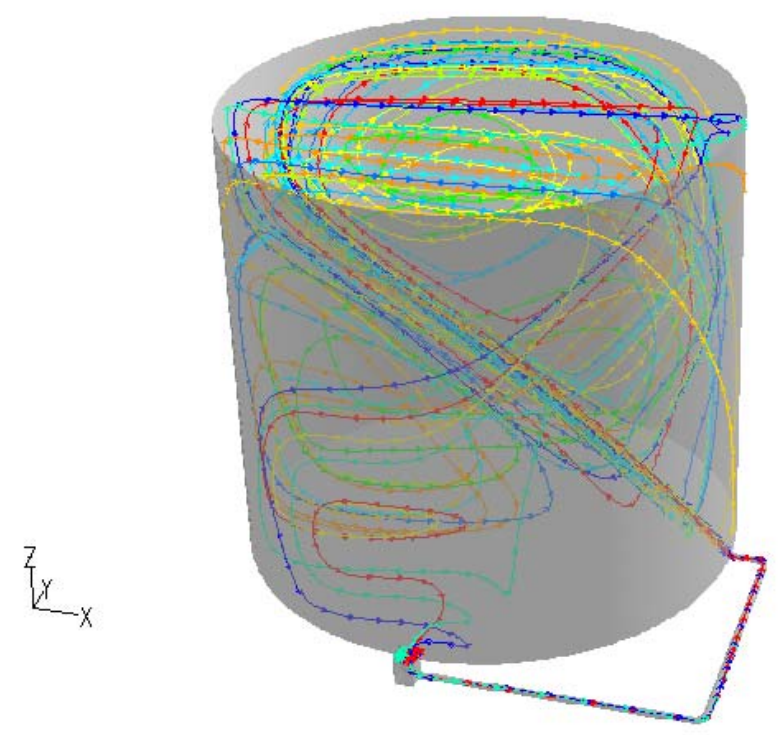

Figure 7. Lagrangian flow path lines from jet inlet to tank exit for fully developed flow circulation inside a tank during blending 
(Nondimensional species conc.)*

0
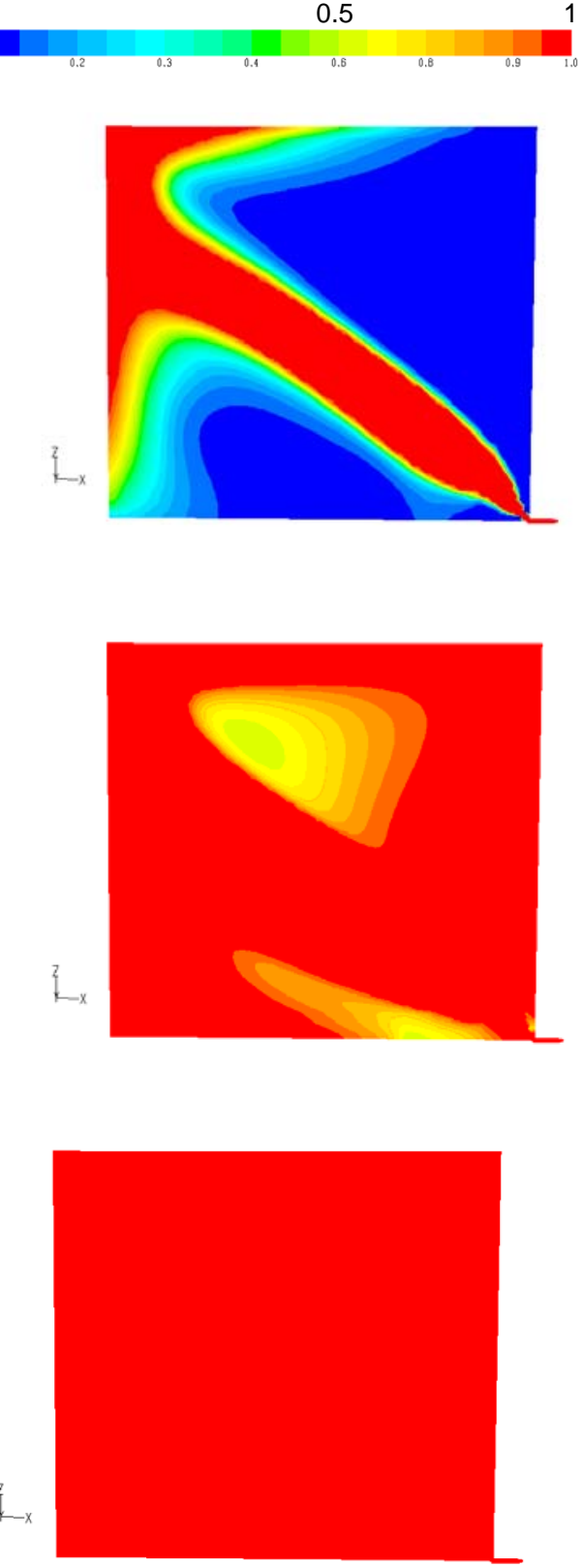

( $t=33$ sec: blending time within 95\% homogeneity)

(Velocity flow patterns)
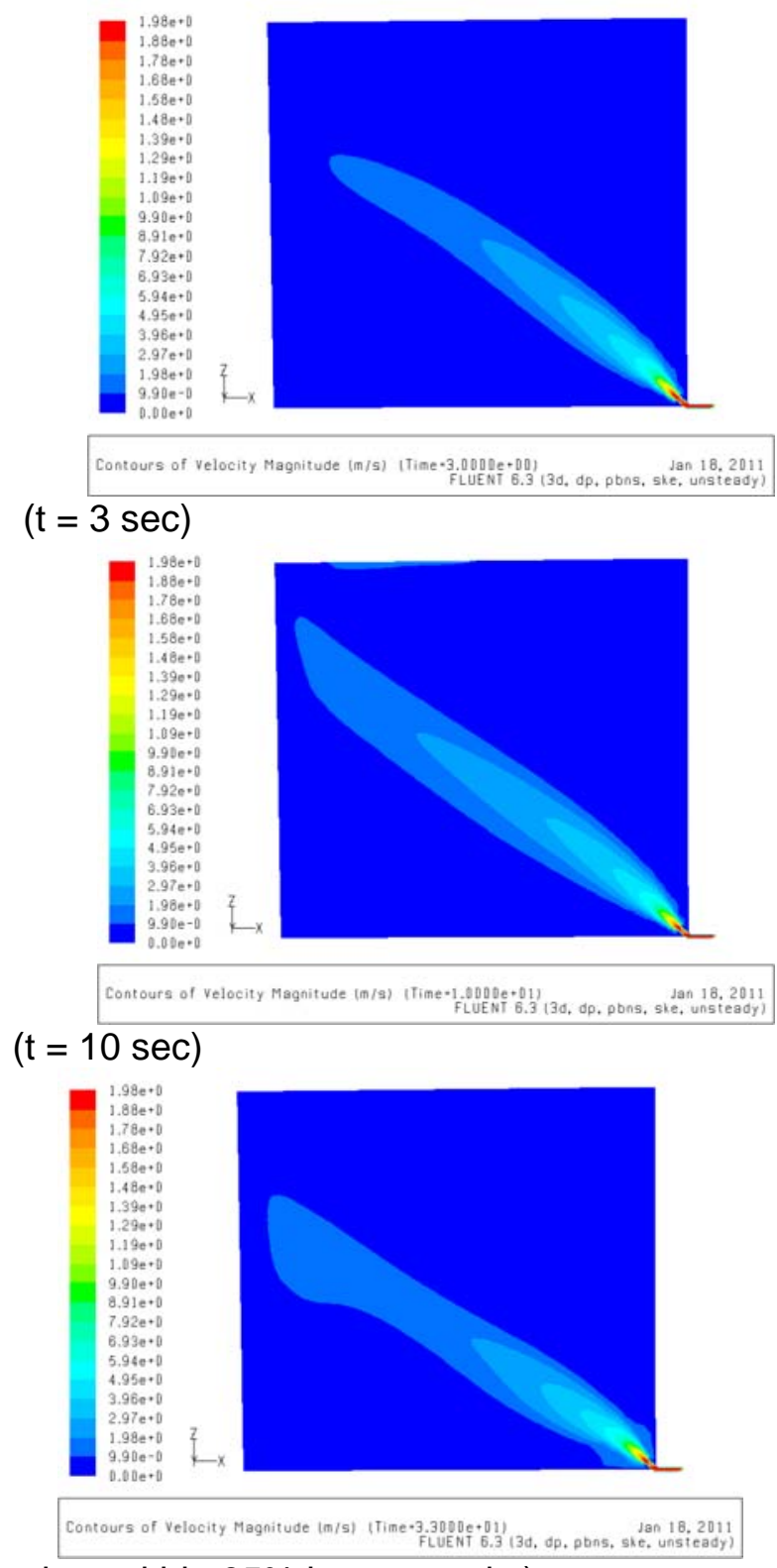

Figure 8. Comparison of transient time snapshots for flow patterns of species concentration at vertical central plane through the pump nozzle center line ( ${ }^{*}$ Non-dimensionalized by equilibrium species concentration of $3.02 \times 10^{-4}$; literature blending time results $=32$ seconds) 
SRNL-STI-2013-00702

Revision 0

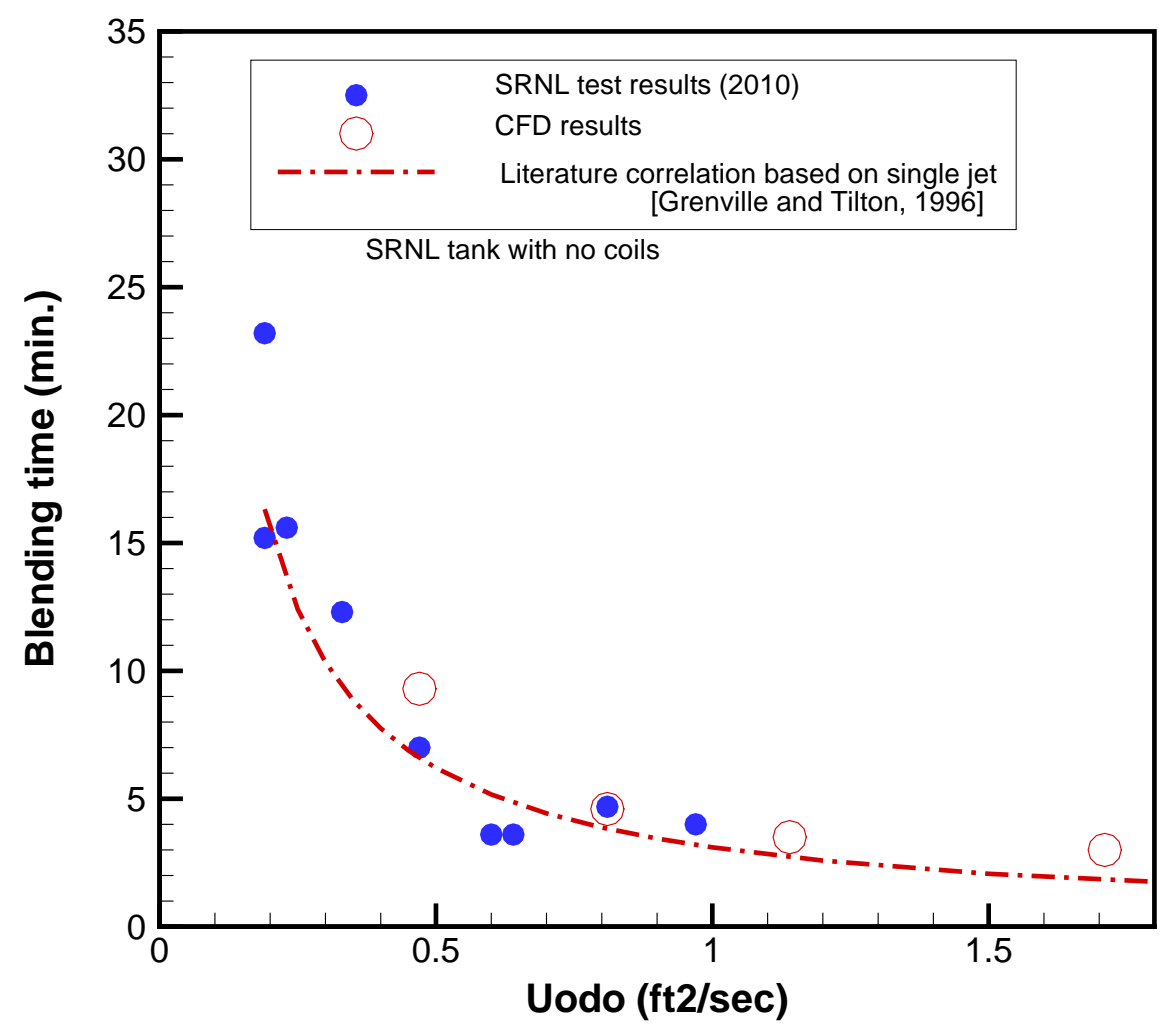

Figure 9. Benchmarking results of theoretical tank blending time compared to experimental test results [6]

\subsection{Performance Results for Mixing Calculations in JT-71/72 Tanks}

The CFD modeling predictions for the mixing time due to the recirculated mainstream velocities along the principal flow direction driven by the pump were benchmarked against the literature results. Based on the validated CFD model, the current work consists of two main goals. One goal is to quantify the mixing operation time that will adequately blend and mix two miscible liquids to obtain a uniform composition in the tank with a minimum level of nonuniform species contents. The other is to verify adequacy of 2.5 hours of pump recirculation for tank species to be well mixed in HB-Line tanks, JT-71/72.

A series of calculations were performed to determine mixing time for potential operating conditions as shown in Table 1. All cases modeled for the analysis are summarized in Table 2. For the performance analysis, the modeling calculations were based on the 15 gpm pump recirculation to evaluate the mixing operations. The results show that the maximum speed is about $2.3 \mathrm{ft} / \mathrm{sec}$ at inlet of the pump located at 1.5 inches above the tank floor, corresponding to $15 \mathrm{gpm}$ circulation flowrate. In this case, the pump is installed at the center of the tank as shown in Fig. 1. 
Figure 10 shows steady state circulation flow patterns and flow distributions before species injection for Case A1, which has low-end density and low-end viscosity of bulk solution and species as shown in Table 2. Maximum and minimum values of transient species mass fractions are observed during the mixing period as presented in Fig. 11. The snapshots of the transient mass fractions for Case A1 are shown in Fig. 12.

The results for all of the modeling cases considered for the analysis are summarized in a quantitative way in Table 4. As shown in Table 1, a maximum mixing time of 35 minutes will be required when two miscible fluids are mixed by one recirculation pump. The addition of the supports to the model adds only a small amount of time to the end result. Any other small obstructions not modeled, such as the air sparge ring, will have a negligible impact on the adequacy of the 2.5 hours of mixing. The modeling calculation results verify adequacy of 2.5 hours of pump recirculation to be considered well mixed in HB-Line tanks, JT-71/72.
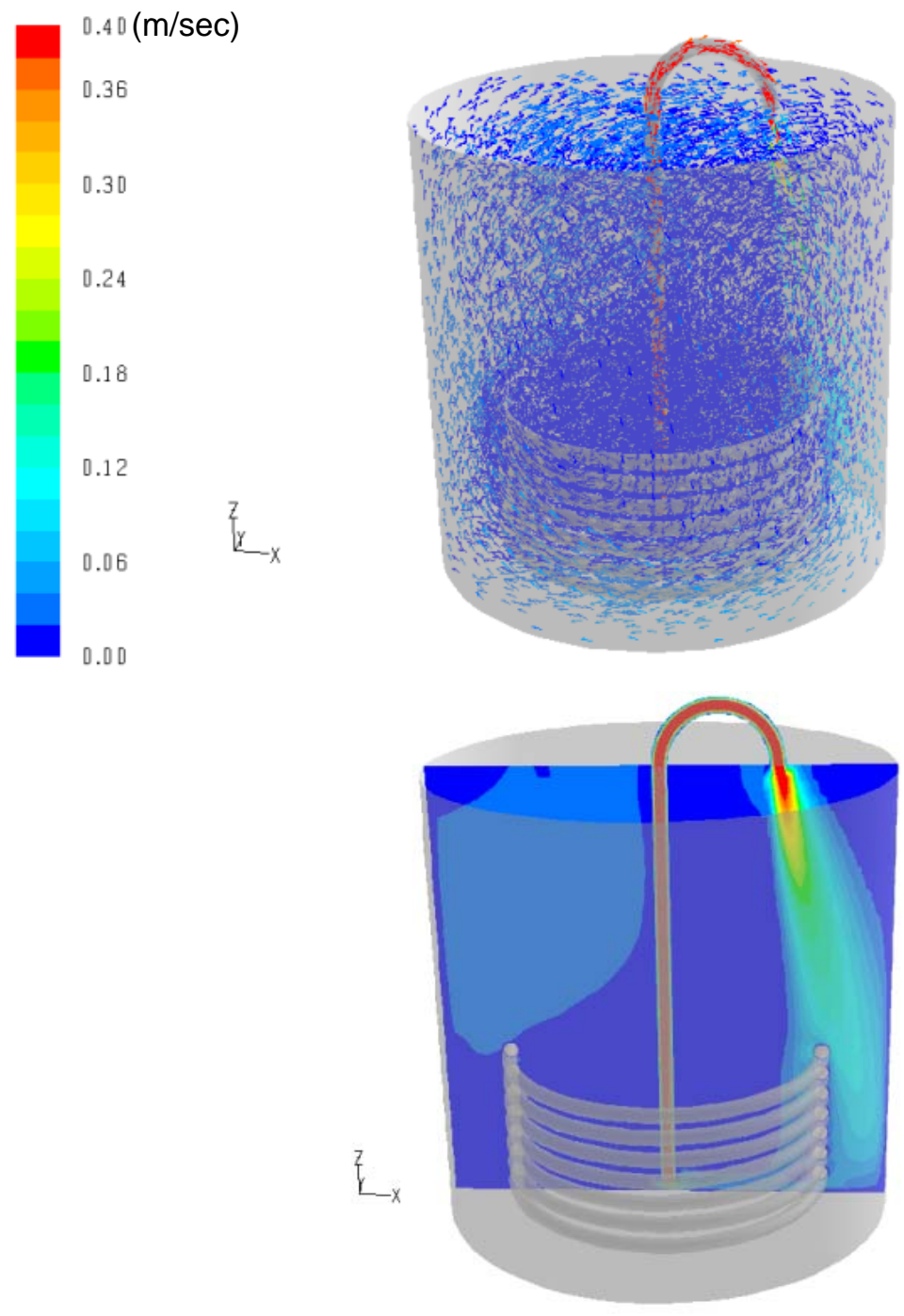

Figure 10. Circulation flow patterns and flow distributions before species injection (Case A1) 


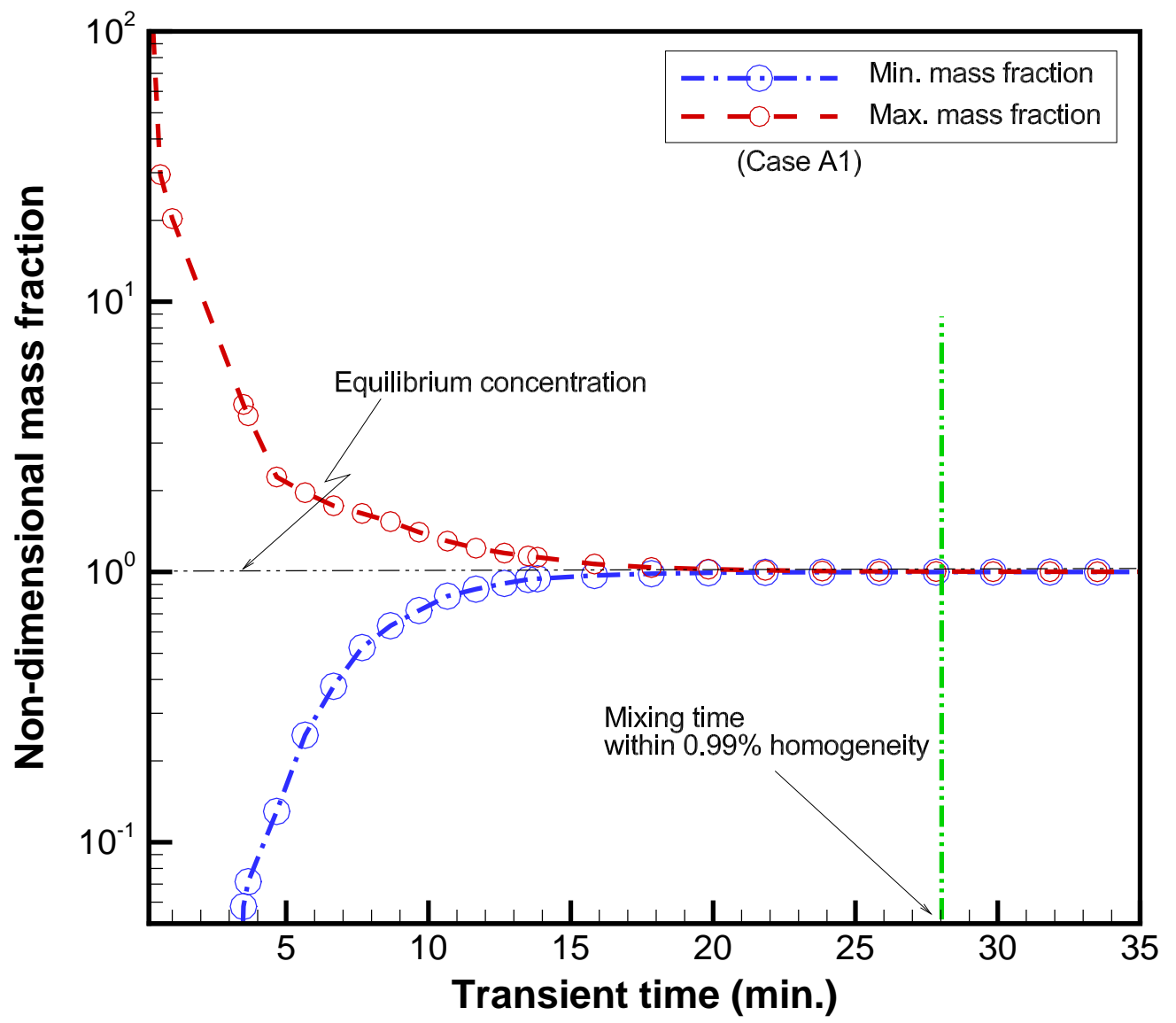

Figure 11. Transient species mass fractions during the mixing period (Case A1). 

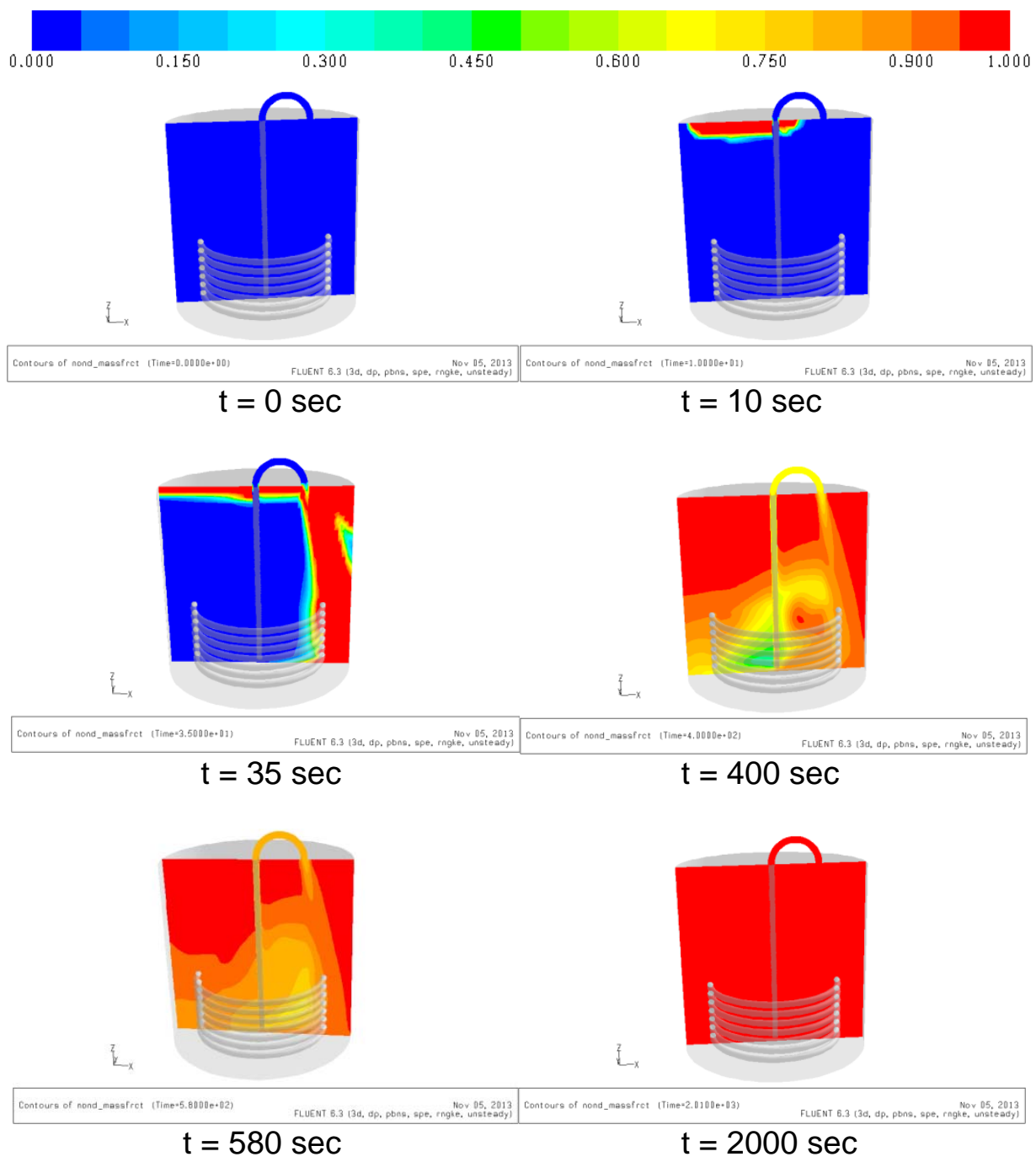

Figure 12. Transient non-dimensional mass fractions for Case A1. 
Table 4. Results for the modeling cases considered for the analysis

\begin{tabular}{|c|c|c|c|c|}
\hline $\begin{array}{l}\text { Modeling } \\
\text { cases }\end{array}$ & $\begin{array}{l}\text { Modeling } \\
\text { geometry }\end{array}$ & \multicolumn{2}{|c|}{ Operating conditions } & Mixing time \\
\hline \multirow{2}{*}{ Case A1 } & \multirow{2}{*}{$\begin{array}{l}\text { Cooling coils } \\
\text { included }\end{array}$} & Bulk fluid & $\begin{array}{c}\text { Specific gravity: } 1.150 \\
\text { Viscosity: } 1 \mathrm{cp}\end{array}$ & \multirow[t]{2}{*}{28} \\
\hline & & $\begin{array}{l}\text { Species to } \\
\text { be mixed }\end{array}$ & $\begin{array}{c}\text { Specific gravity: } 1.100 \\
\text { Viscosity: } 1 \mathrm{cp}\end{array}$ & \\
\hline \multirow{2}{*}{ Case A2 } & \multirow{2}{*}{$\begin{array}{l}\text { Cooling coils } \\
\text { included }\end{array}$} & Bulk fluid & $\begin{array}{c}\text { Specific gravity: } 1.235 \\
\text { Viscositv: } 3 \mathrm{cp}\end{array}$ & \multirow{2}{*}{31} \\
\hline & & $\begin{array}{l}\text { Species to } \\
\text { be mixed }\end{array}$ & $\begin{array}{l}\text { Specific gravity: } 1.235 \\
\text { Viscosity: } 3 \mathrm{cp}\end{array}$ & \\
\hline \multirow{2}{*}{ Case A3 } & \multirow{2}{*}{$\begin{array}{l}\text { Cooling coils } \\
\text { included }\end{array}$} & Bulk fluid & $\begin{array}{c}\text { Specific gravity: } 1.235 \\
\text { Viscosity: } 3 \mathrm{cp}\end{array}$ & \multirow[t]{2}{*}{29} \\
\hline & & $\begin{array}{l}\text { Species to } \\
\text { be mixed }\end{array}$ & $\begin{array}{l}\text { Specific gravity: } 1.0 \\
\text { Viscosity: } 1 \mathrm{cp}\end{array}$ & \\
\hline \multirow{2}{*}{ Case B } & \multirow{2}{*}{$\begin{array}{l}\text { Cooling coils and } \\
\text { supporting } \\
\text { structures included }\end{array}$} & Bulk fluid & $\begin{array}{c}\text { Specific gravity: } 1.235 \\
\text { Viscosity: } 3 \mathrm{cp}\end{array}$ & \multirow[t]{2}{*}{35} \\
\hline & & $\begin{array}{l}\text { Species to } \\
\text { be mixed }\end{array}$ & $\begin{array}{l}\text { Specific gravity: } 1.0 \\
\text { Viscosity: } 1 \mathrm{cp}\end{array}$ & \\
\hline
\end{tabular}

\subsection{Summary}

All modeling calculations for the mixing operations of miscible fluids contained in HBLine tanks, JT-71/72, were performed by taking a three-dimensional Computational Fluid Dynamics (CFD) approach. The CFD modeling results were benchmarked against the literature results [5] and the previous SRNL test results [2] to validate the model. Final performance calculations were performed by using the validated model to quantify the mixing time for the HB-Line tanks. The mixing study results for the JT-71/72 tanks show that, for the cases modeled, the mixing time required for the blending of tank contents is no more than 35 minutes, which is well below 2.5 hours of recirculation pump operation. Therefore, the results demonstrate the adequacy of 2.5 hours' mixing time of the tank contents by one recirculation pump to get well mixed. 


\subsection{References}

1. Drawing \# for Column Feed Tank, D127930

2. S. Y. Lee, R. A. Leishear, and M. R. Poirier, "Tank 21 and Tank 24 Blend and Feed Study: Blending Times, Settling Times, and Transfers", SRNL-STI-2012-00306, May 2012.

3. S. Y. Lee, R. A. Dimenna, R. A. Leishear, and D. B. Stefanko, "Analysis of Turbulent Mixing Jets in a Large Scale Tank", ASME Journal of Fluids Engineering, Volu 130, Number 1, 2008, p. 011104.

4. ANSYS FLUENT 6.3, September 2010.

5. R. K. Grenville, and J. N. Tilton, "A New Theory Improves the Correlation of Blend Time Data from Turbulent Jet Mixed Vessels", Trans. Inst. of Chem. Eng., Vol. 74, Part A., 1996, pp. 390-396.

6. S. Y. Lee and B. W. Armstrong, "SDI CFD Modeling Analysis", SRNL-STI-201100025, April 2011

7. Jones, W. P. and Launder, B. E., 1972, "The Prediction of Laminarization with a Two-Equation Model of Turbulence”, Int. J. of Heat Mass Transfer, vol. 15, pp. 301314, 1972. 